\title{
SEGUNDO LUGAR
}

\section{Inclusión de los derechos de las audiencias en el modelo de medios públicos: participación de las audiencias como ciudadanos e interlocutores legítimos}

Laura Martínez Aguilar

Universidad Nacional Autónoma de México

\section{Asesora del trabajo recepcional: Dra. Luz María Garay Garay}

\section{RESUMEN}

La presente investigación tuvo como punto de partida la reforma constitucional de telecomunicaciones y radiodifusión de 2013, con la subsecuente Ley Federal de Telecomunicaciones y Radiodifusión y la Ley Federal del Sistema Mexicano de Radiodifusión Pública, de 2014.

El sustento es que, resultado de dicha reforma constitucional, en México se transita a la existencia distintos tipos de concesión, para un diferido uso del espectro radioeléctrico de los medios de radiodifusión; lo cual permitió el reconocimiento de unos nuevos actores: los medios públicos y las audiencias en calidad de ciudadanos, a través de los derechos de las audiencias.

En este texto se presenta una síntesis para cada uno de los cuatro apartados de la investigación. MEDIOS PÚBLICOS: ¿QUÉ ES LO PÚBLICO?

La importancia de discutir los derechos de las audiencias y medios públicos a la luz de la reforma a las telecomunicaciones y la radiodifusión de 2013, en una tesis de licenciatura, es que ésta representa una partición de lo sensible entendida por Jacques Rancière como:

El sistema de hechos auto-evidentes que simultáneamente descubren la existencia de algo en común, así como las delimitaciones que definen a las respectivas partes y posiciones que ocupan dentro de él (lo común) (2011, p. 12).

Es decir, lo sensible es un espacio en común en continua definición y delimitación de las partes que son reconocidas dentro de él: "la división de lo sensible revela quién puede tener parte en aque- 
llo que es común para la comunidad", con base en "lo que hacen y en el tiempo-espacio en que esa actividad es llevada a cabo" (2011, p. 12).

En este sentido, ha habido un doble reconocimiento de quienes ahora tienen parte dentro de un espacio en común, en el espacio del ejercicio de derechos comunicativos: las audiencias mediante los derechos de las audiencias, pero al mismo tiempo, el espacio en común de la comunicación son los medios de uso público, mediante la existencia de los distintos tipos de concesión de uso del espectro radioeléctrico, con la específica existencia de los medios de uso público: aquellos en los cuales tanto la reforma constitucional de 2013 y la ley reglamentaria de 2016 señalan que los medios de uso público deben encontrar mecanismos para la participación ciudadana y garantizar a las audiencias el acceso a estos medios.

Resulta primordial entender el concepto de lo público y del espacio público. Jürgen Habermas lo define como "un espacio público que las personas privadas usan como medio de crítica permanente y que cambia las condiciones de legitimación” (1999, p. 435). Es decir, en el espacio público, tanto medios de comunicación como las audiencias tienen cabida en la medida de que, a diferencia de la esfera pública, el espacio público es el lugar en donde existen se vierten y visibilizan, pero no se argumentan deliberativamente, las opiniones y los temas de la res pública.

Este acercamiento al espacio público para la comprensión de los medios públicos deja entrever varios retos para los medios de uso público: desligarse de la estructura gubernamental para proyectarse como medios para la sociedad y, al mismo tiempo, convivir además de ser una alternativa, ante los medios de uso comercial. Ante esta realidad, Martín Becerra apunta:

Un medio público sin público, es decir, sin audiencias, es una contradicción [...]. La apuesta por desarrollar emisoras con perfil cultural por parte del Estado debe asumir, por un lado, la ubicuidad de los consumos audiovisuales actuales y proponer narrativas transmediales y, por otro, articular lo cultural con el entretenimiento (2015, p. 97).

De ahí que, realizar una lectura a los medios de comunicación de uso público, luego de una reforma constitucional plantea la posibilidad de repensar al Estado no solo como el regulador de los actores que intervienen en el espacio público (Rancière y lo policial), sino también el rol que esos actores representan en un sentido político, cultural y social más amplio. 


\section{AUDIENCIAS ACTIVAS: NO MÁS RECEPTORES PASIVOS NI PÚBLICO-MASA}

Partiendo de lo anterior, y dado que se trata de una investigación comunicacional, se partió del supuesto de que, para pensar en los derechos de audiencias como un principio de participación social, el concepto de correspondía acuñar, desde las Ciencias de la Comunicación, es el de audiencias activas; como según señala Jesús Martín-Barbero (2010): entes creadores de sentido a partir de las matrices culturales, con base en las cuales es posible un vínculo entre la cultura y la política, contribuye al ejercicio efectivo de los derechos de las audiencias.

Además, la inclusión participativa de las audiencias activas dentro de la organización de los medios públicos contribuye, en conjunto, al carácter ideal de democráticos, plurales e incluyentes (Ortega, 2006) a dichos medios. Ahora bien, la definición principal del constructo audiencias activas es que "se trata de sujetos capaces de entablar mediaciones con los contenidos consumidos a través de los medios de comunicación bajo el entendido de que al mismo tiempo son audiencia y ciudadanos" (Orozco, 1997).

Con fundamento en la teoría de las mediaciones de Jesús Martín-Barbero y la definición aquí acuñada por Guillermo Orozco, en esta investigación se partió del entendimiento de que no existen audiencias pasivas, en tanto éstas eligen a qué medios de comunicación acercarse, qué contenidos revisar en estos medios; aunado a la interpretación de los contenidos mediáticos, la asimilación de significados y la producción de sentidos que guían y orientan la vida cotidiana de las audiencias, lo cual es un fenómeno indisociable a la recepción mediática o al hecho mismo de cómo se construye el imaginario acerca de ser ciudadano.

Este último punto es crucial en la consideración de la audiencia activa, pues reconoce el papel fundamental de los intercambios culturales a partir de la ritualidad, la tecnicidad y la institucionalidad con base en las competencias de recepción del sujeto; al mismo tiempo, sitúa a la audiencia en su rol de ciudadano, postura a partir de la cual se comprende a "la política desde la comunicación como procesos de intercambios simbólicos e imaginarios para la conformación de poder" (Martín-Barbero, 2010, p. XXIV). Es decir, el consumo mediático no solo es activo, sino también ciudadano.

Ser audiencia activa se entiende en esta investigación como una variable independiente, más no excluyente, a la existencia de audiencias críticas, que pueden encontrarse politizadas, mantenerse al tanto de los cambios y prácticas del medio de comunicación; o bien, tener un rol de receptores sin 
un mayor involucramiento con los contenidos del medio. De ahí el énfasis de que, aparte de ser audiencias activas, deban tener un rol participativo dentro de los medios públicos.

\section{LEGISLACIÓN DE MEDIOS EN MÉXICO: LA PARTICIÓN DE LO SENSIBLE DE 2013}

Estas dos primeras partes abreviadas justifican que el tercer apartado de la investigación se centre en el análisis y discusión sobre las leyes sobre medios de comunicación en México, desde la Ley sobre Delitos de Imprenta (la cual, si bien no es radiodifusión, sí es vigente en cuanto a la discusión sobre la libertad de expresión), hasta la reforma constitucional de 2013 y la Ley Reglamentaria de 2014.

Era importante detenerse en el marco legal desde el que se sientan las bases para el reconocimiento de actores mediáticos en tanto, a partir de una lectura a Jacques Rancière, el marco jurídico representa un orden policial. La policía o lo policial para Rancière es "en su esencia, la ley generalmente implícita, que define la parte o la ausencia de partes [...] un orden de cuerpos que definen los modos del hacer, los modos del ser y los modos del decir" (1996, p. 44).

Esto significa que si una reforma constitucional representa una partición de lo sensible (el planteamiento aquí discutido), en tanto lo sensible dicta a quienes se les reconoce como parte integrante del espacio en común, una partición de lo sensible conlleva, ineludiblemente, a un reordenamiento de lo policial: en este caso: los derechos de las audiencias son aplicables a todos los medios de comunicación mexicanos, sin importar su tipo de concesión; ahí yace un “orden de cuerpos”: medio público o medio comercial; un cambio: público, receptor o audiencia; unos modos del ser y del hacer: audiencias con derechos (es decir, una subjetivación de los actores referidos).

Esta comprensión acerca de la reforma a telecomunicaciones brinda un panorama más amplio para señalar por qué nuevos actores reconocidos no solo se integran en sumatoria a lo ya existente, sino que generan un nuevo espacio, una nueva forma de concebir la legislación de medios y la concentración mediática en función de las audiencias, pues se encuentran reconocidas en la ley.

\section{LAS AUDIENCIAS EN CALIDAD DE CIUDADANOS E INTERLOCUTORES}

Por último, en la tesis el cuarto capítulo sustenta cómo la práctica de los derechos de las audiencias se vincula con un ejercicio de ciudadanía, pero también de reconocimiento como interlocutores legítimos a esos nuevos actores del espacio en común: las audiencias. 
Lo anterior va de la mano con el claro matiz de que los medios públicos constituyen el punto de entrada para las audiencias activas como interlocutores legítimos. En la necesidad de un medio público y no gubernamental, que no incurra en "la subestimación intelectual de selección de las audiencias, que si contaran con voces divergentes al relato oficial podrían elaborar con mayor fundamento sus propias perspectivas" (Becerra, 2015, p. 92).

Asimismo, se plantea un nivel de discusión acerca de la ciudadanía no restrictivo a la institucionalidad de la misma ciudadanía: el voto, pago de impuestos o servicio militar; sino "la ciudadanía como subjetivación representa la concepción de lo político. En consecuencia, los actores de la ciudadanía no pueden ser definidos por adelantado a partir del análisis de una escala o sitio dados; los cuales son sus otras categorías centrales" (Isin, 2009, p. 370).

Es decir, que el ejercicio de los derechos de las audiencias, particularmente en los medios de uso público (en tanto estos garanticen los mecanismos de una participación ciudadana) subjetivan, dan voz y reconocimiento a las audiencias-ciudadanos con derechos y necesidades. Una posibilidad no de democratización de los medios, pero quizá sí de la democratización del vínculo de los medios de comunicación con sus audiencias. 